\title{
Multidrug Resistant Escherichia coli in Nosocomial Urinary Tract Infections at a Tertiary Care Hospital in Kerala, India
}

\author{
Gufran Ahmed M. Bijapur ${ }^{1}$, Saleel V. Maulingkar ${ }^{*}, 2$, B. Greeshma ${ }^{1}$ and Shaik Mohammed Usman ${ }^{1}$ \\ ${ }^{1}$ Department of Microbiology, Kannur Medical College, Anjarakandy-670612, India \\ ${ }^{2}$ Department of Microbiology, DMWIMS Medical College, Meppadi-673577, India
}

\begin{abstract}
Background: Nosocomial UTI (NUTI) is a major cause of morbidity in hospitalized patients and presence of urinary catheter is its single most important predisposing factor. Antibiotic resistance is a problem in these infections.

Objectives: To estimate the prevalence of NUTI in our setting, identify the predisposing factors and etiological agents of NUTI; to determine the antibiotic susceptibility patterns of the pathogens; to identify the risk factors for the acquisition of antibiotic resistance in these patients and to study the effect of duration of catheterization on the nature of infection.

Materials and Methods: After identifying suspected cases of NUTI based on signs and symptoms, relevant clinical details were noted and the urine samples were collected aseptically and cultured on blood agar and MacConkey's agar using the calibrated-loop-semi-quantitative method. Isolates from samples with significant bacteriuria were identified. Antibiotic susceptibility test was performed using modified Kirby-Bauer disk diffusion method. Resistance of the $E$. coli isolates to fluoroquinolones and third generation cephalosporins was confirmed by minimum inhibitory concentration (MIC) using agar dilution method for ciprofloxacin and cefotaxime respectively.

Results: Catheterization was the most common (88.1\%) predisposing factor for NUTI. E. coli was the most common single isolate, accounting for $96(41.2 \%)$ of the total 233 isolates. Multidrug resistance was observed in $81(84.37 \%)$ of $E$. coli isolates. High rates of resistance were found with ampicillin (91.66\%), ciprofloxacin (75\%), cotrimoxazole (71.87\%), cefuroxime $(82.29 \%)$, cefotaxime $(79.16 \%)$, cefepime $(67.7 \%)$ and amoxicillin/clavulanate $(63.54 \%)$ among the E. coli isolates. However, imipenem ( $0 \%$ resistance), meropenem( $0 \%)$, piperacillin-tazobactam $(15.62 \%)$, amikacin $(5.2 \%)$ and nitrofurantoin (26.04\%) appeared to have retained greater activity.

Conclusion: Considering the high rates of resistance found with fluoroquinolones, ampicillin, cotrimoxazole and cephalosporins, these can no longer be recommended for empiric therapy of NUTIs. Instead, imipenem, pipericillintazobactam, amikacin and nitrofurantoin should be considered for initial therapy with prompt de-escalation following receipt of the culture and sensitivity result.
\end{abstract}

Keywords: Catheterization, E. coli, multidrug resistance, nosocomial urinary tract infection.

\section{INTRODUCTION}

Nosocomial urinary tract infection (NUTI) accounts for over 1 million cases annually and approximately $40 \%$ of all nosocomial infections $[1,2]$. Catheter associated UTIs (CAUTI) constitute $80 \%$ of all nosocomial UTIs [3]. "Almost 100 million catheters are sold annually worldwide" [4]. "NUTIs are significant not only due their high incidence and subsequent economic cost (an estimated \$424 million to $\$ 451$ million spent annually in the United States to manage these infections)" [5] but also because they may lead to serious complications, prolong the hospital stay, cause often unnecessary antibiotic usage and encourage the development of antibiotic resistance among hospital bacterial strains. The etiology, risk factors, pathogenesis, methods of diagnosis and surveillance, clinical outcome and effectiveness of preventive and therapeutic measures are now largely known

*Address correspondence to this author at the Department of Microbiology, DMWIMS Medical College, Meppadi-673577, India; Tel: 09048202446;

E-mail: saleemaulingkar@yahoo.com
[6]. Further, in recent years, resistance of these uropathogens to antibiotics has increased [7-13] Besides, the etiological agents and drug resistance vary among hospitals and through time [14] Therefore, it is imperative to know the bacterial pathogens responsible for NUTI in a particular setting and monitor their antibiotic susceptibility patterns periodically as it would be helpful in improving the efficacy of empirical treatment.

\section{MATERIALS AND METHODS}

\section{Patients}

This study was conducted between April 2013 and March 2014 at Kannur Medical College Hospital, Anjarakandy, Kerala, India. A UTI was considered as nosocomial if it was neither present nor incubating when the patient was admitted to the hospital and developed two days after hospitalization $[15,16]$ or up to 48 hours after discharge from the hospital. It also applied to those patients who were transferred from another hospital and those who were readmitted to the 
hospital because of a UTI. Diagnosis was made as per the CDC definition of NUTI [17] i.e., symptomatic infection with the presence of one of the following signs or symptoms - fever, urgency, increased frequency of urination, dysuria, and a urine culture of $>10^{5} \mathrm{CFU} / \mathrm{ml}[18]$ with no more than two species of organisms [19]. Patients were included from all the wards in the hospital. Of the 9544 patients admitted to the hospital during the study, we collected clinical data with respect to the presence of signs and symptoms of a urinary tract infection. Those with signs and symptoms were requested to provide a urinary specimen, or a specimen was collected directly from the urinary catheter. Patients with a positive urine culture were included in the analysis if the diagnosed UTI could be considered to be nosocomial. Clinical data obtained with regard to finding the associated factors for NUTI in each patient included age, gender, duration of hospital stay, underlying disease, other comorbid conditions; whether catheterized and if so, the duration of catheterization; details of antibiotic therapy, other instrumentation of the genitourinary tract and presence of signs and symptoms of UTI. Clinical data also included past history (one year) of UTI, previous (six months) exposure to antibiotics, previous (one year) history of urinary catheterization and older age ( $>65$ years).

\section{Specimen Collection}

To obtain urine sample from a catheterized patient, the soft rubber connector between the catheter and the collecting tube was clamped by means of a sterile artery forceps for ten minutes for urine to collect. The rubber tube was disinfected with surgical spirit. It was then punctured by means of a sterile syringe and needle and urine aspirated. In patients who were not on catheter, clean-catch midstream sample was collected.

\section{Processing and Culture}

The urine samples were processed within one hour of collection. Wet mount and Gram's smear were used to detect cellular exudates and bacteria. Calibrated loop $(4 \mathrm{~mm}-$ internal diameter, carrying $0.04 \mathrm{ml}$ urine) method was used to inoculate blood agar and MacConkey's agar plates. The inoculated plates were incubated at $37 \mathrm{oC}$ for 24 to 48 hours. Bacteria grown in colony counts $\geq 10^{5} \mathrm{CFU} / \mathrm{ml}$ were considered positive [20]. The bacterial species were identified using standard methods [21].

\section{Antibiotic Susceptibility Testing}

E. coli isolates grown in significant colony counts were subjected to antibiotic susceptibility testing using modified Kirby-Bauer disk diffusion method as recommended by the CLSI [22]. E. coli ATCC 25922 was used as the reference strain. The antibiotic discs used were ampicillin, amikacin, gentamicin, ciprofloxacin, ofloxacin, cotrimoxazole, cefuroxime, cefotaxime, ceftazidime, cefixime, cefepime, nitrofurantoin, nalidixic acid, amoxicillin/clavulanate, piperacillin/tazobactam and imipenem for gram negative isolates. Results were interpreted as sensitive, intermediate or resistant according to CLSI criteria [22] "For calculations, all isolates showing zone of inhibition indicating intermediate susceptibility were considered resistant. Multidrug resistance (MDR) isolates were defined as those isolates having co-resistance to at least three different antibiotic classes" [23]. Resistance of the MDR E. coli isolates to each of the antibiotic tested was confirmed by Minimum Inhibitory Concentration (MIC) using agar dilution method according to CLSI guidelines [22, 24]. Extended spectrum beta-lactamase (ESBL) production was detected phenotypically by the combined disc diffusion method using cefotaxime $(30 \mu \mathrm{g})$ and cefotaxime/clavulanic acid $(30 / 10 \mu \mathrm{g}) ;$ and ceftazidime $(30 \mu \mathrm{g})$ and ceftazidime/clavulanic acid $(30 / 10 \mu \mathrm{g})$ according to CLSI guidelines [22].

\section{RESULTS}

For the study, we screened 9544 patients, of whom 221 reported to have signs and/or symptoms of UTI. Of these, 193 fulfilled the definition of NUTI and were included in the final analysis, proving 233 strains. Out of 193 cases, 170 cases $(88.1 \%)$ were Catheter Associated UTIs (CAUTIs) and $23(11.9 \%)$ were not associated with catheter use. More than two-thirds $(68.38 \%)$ of the patients were older than 51 years. Out of the total 193 patients, $115(59.58 \%)$ were males and 78 (40.42\%), females.

Most patients had multiple co morbid conditions in addition to UTI. Prominent among them were diabetes mellitus in 50 patients $(30.57 \%)$, nephropathies causing renal insufficiency in 38 patients $(19.67 \%)$, neurological conditions including stroke and degenerative disorders in 28 patients $(14.51 \%)$, prostatic hyperplasia in 33 patients (17.1\%) and cancers in 12 patients $(6.22 \%)$. A high number of patients - 66 patients $(34.2 \%)$ gave past history of hospitalization(prior to 6 months).

The effect of duration of catheterization on bacteriuria was studied (Table 1).

The majority of patients with a CAUTI were catheterized for more than 1 week up to 1 month $(53.3 \%)$, while $36.5 \%$ of the patients had a catheter for up to 1 week only. Longer duration of catheterization was associated with a higher frequency of poly-microbial infections. (Table 1)

A total of 233 strains were isolated out of 193 cases of NUTI (Table 2).

One hundred and fifty three cases $(64.56 \%)$ were monomicrobial infections and 40 cases $(35.44 \%)$ were bimicrobial infections. E. coli was the commonest [96 isolates, $(41.2 \%)]$ pathogen isolated. Enterococcus faecalis and Proteus vulgaris were isolated more often in poly-microbial infections than in mono-microbial infections (Table 2).

Antibiotic susceptibility testing was done on E. coli strains against 16 antibiotics. They were found to have high resistance rates. (Table $\mathbf{3}$ ).

An attempt was made to identify the presence of known risk factors for acquisition of antibiotic resistance in the patients. Out of 193 patients, 149 (77.2\%) gave history of prior (six months) antibiotic exposure, $61(31.6 \%)$ had prior (one year) UTI, $64(33.16 \%)$ had prior (one year) catheterization and $39(20.2 \%)$ were aged $>65$ years. 
Table 1. Duration of catheterization and nature of infection.

\begin{tabular}{|c|c|c|c|}
\hline Duration of Catheterisation & Mono-Microbial Infections (\%) & Poly-Microbial Infections (\%) & Total \\
\hline \hline Upto 7 days & $56(90.32)$ & $6(9.68)$ & 62 \\
\hline$>7$ days - 30 days & $69(85.83)$ & $22(24.17)$ & 36.47 \\
\hline$>30$ days & $5(29.41)$ & $12(70.59)$ & 53.53 \\
\hline Total & 130 & 40 & 17 \\
\hline
\end{tabular}

Table 2. Bacterial Pathogens in NUTI.

\begin{tabular}{|c|c|c|c|}
\hline Isolate & Monomicrobial & Polymicrobial & Total (\%) n=233 \\
\hline \hline Escherichia coli & 66 & 30 & $96(41.20)$ \\
\hline Klebsiella pneumoniae & 27 & 16 & $35(15.02)$ \\
\hline Enterococcus spp. & 12 & 11 & $28(12.02)$ \\
\hline Pseudomonas aeruginosa & 13 & 3 & $24(10.30)$ \\
\hline Candida albicans & 17 & 6 & $20(8.58)$ \\
\hline Proteus vulgaris & 5 & 1 & $11(4.72)$ \\
\hline Citrobacter freundii & 6 & 1 & $7(3.0)$ \\
\hline Acinetobacter baumannii & 3 & 2 & $4(1.71)$ \\
\hline Coagulase Negative Staphylococcal species & 2 & 2 & $4(1.71)$ \\
\hline Enterobacter cloacae & 2 & 80 & $4(1.71)$ \\
\hline Total & 153 & & $233(100)$ \\
\hline
\end{tabular}

Table 3. Antibiotic resistance in $E$. coli isolated from NUTI.

\begin{tabular}{|c|c|c|c|}
\hline \multirow{2}{*}{ Antibiotics (Disk Potency) } & \multicolumn{3}{|c|}{ Number (\%) of Resistant Isolates } \\
\hline & ESBL-ve n=19(19.8) & ESBL+ve n=77(80.2) & Total $(n=96)$ \\
\hline Ampicillin & $11(57.9)$ & $77(100)$ & $88(91.7)$ \\
\hline Gentamicin & $02(10.5)$ & $25(32.4)$ & $27(28.1)$ \\
\hline Amikacin & $00(00)$ & $05(6.5)$ & $05(5.2)$ \\
\hline Cotrimoxazole & $08(42.1)$ & $61(79.2)$ & $69(71.8)$ \\
\hline Ciprofloxacin & $04(21.1)$ & $68(88.3)$ & $72(75)$ \\
\hline Ofloxacin & $03(15.8)$ & $65(84.4)$ & $68(70.8)$ \\
\hline Nalidixic acid & $10(52.6)$ & $72(93.5)$ & $82(85.4)$ \\
\hline Nitrofurantoin & $04(21.1)$ & $21(27.2)$ & $25(26.0)$ \\
\hline Cefuroxime & $02(10.5)$ & $77(100)$ & $79(82.2)$ \\
\hline Cefixime & $01(05.2)$ & $77(100)$ & $78(81.2)$ \\
\hline Cefotaxime & $00(00)$ & $77(100)$ & $77(80.2)$ \\
\hline Ceftazidime & $00(00)$ & $77(100)$ & $62(80.2)$ \\
\hline Cefepime & $00(00)$ & $77(100)$ & $65(80.2)$ \\
\hline Amoxicillin/clavulanate & $00(00)$ & $61(79.2)$ & $61(63.5)$ \\
\hline Piperacillin/tazobactam & $00(00)$ & $15(19.4)$ & $15(15.6)$ \\
\hline Imipenem & $00(00)$ & $00(00)$ & $00(00)$ \\
\hline
\end{tabular}




\section{DISCUSSION}

"NUTI is the most common hospital acquired infection with the implications in terms of number of patients affected, duration of excess hospital stay and overall costs are huge $[25,26]$. In our study, we reported a period prevalence of NUTI of $2.31 \%(193 / 9544)$. The most common causative specimen was Escherichia coli, which showed a high level of resistance for a wide variety of antibiotics.

Some of the risk factors for the development of NUTI as evaluated by previous studies are female sex, older age ( $>50$ years), rapidly fatal underlying disease, orthopaedic or urologic patients, urethral catheterization, prolonged duration of catheterization, diabetes mellitus and renal insufficiency [26-29]. The most important determinant for bacteriuria is the duration of catheterization [25]. In the present study, $88 \%$ of NUTIs were found to be catheter associated and a high percentage $(63.5 \%)$ of these patients were on catheter for more than one week.

There is a clear distinction between NUTI and community acquired UTI with respect to their microbial profiles $[3,30]$. E. coli constituted $40.5 \%$ of the total isolates in the present study whereas it has been shown to cause $90 \%$ of the community acquired UTIs [30]. The preponderance of E. coli as a urinary pathogen can be explained in parts by the Prevalence Theory which postulates that the strains responsible for UTI are merely those present in feces and the Specific Pathogenicity Theory which states that those E. coli which possess specific virulence factors - which most commensals probably lack-are uropathogenic [32]. But E. coli causing NUTI lack many of the virulent factors possessed by those causing community acquired UTI [33].

We found that as the duration of catheterization increased, the incidence of poly-microbial infections also increased. We further observed that $E$. coli and enterococci occurred as the most common combination in poly-microbial infections. Moreover, enterococci were the second most common isolates from poly-microbial infections next only to E. coli. Enterococci may aggravate the pathogenicity of coexisting bacteria [34].

The high antibiotic resistance rates in E. coli causing UTI found by us was quite alarming although not entirely surprising. Out of the 96 isolates, 77 were ESBL producers and 81 were multidrug resistant. High rates of resistance were found with ampicillin (91.66\%), ciprofloxacin (75\%), cotrimoxazole $(71.87 \%)$, cefuroxime $(82.29 \%)$, cefotaxime $(79.16 \%)$, cefepime $(67.7 \%)$ and amoxicillin/clavulanate $(63.54 \%)$. High rates of antibiotic resistance among uropathogens in hospital settings have also been shown by previous studies [7-13].

Among the factors that contribute to these high rates of antibiotic resistance are the selection of mutant strains from the patients' own flora receiving antibiotic treatment and the transfer of genetic determinants of resistance e.g., plasmids or transposons. The selection may be enhanced by antibiotic pressure, immunosuppression, presence of foreign body viz., the catheter that impedes the local host defenses and favors colonization. Subsequently, these resistant strains spread among patients in the hospital - the transmission occurring mainly by cross-contamination via the hands of the health care staff. "Factors predisposing to this transmission include the length of hospital stay, intensity and duration of exposure to antibiotics, severity of underlying illness and use of catheter" [33].

To address the growing concerns of antibiotic resistance in hospitals, in addition to stringent infection control precautions, excessive and injudicious use of antibiotics particularly those having broad spectrum activity needs to be aggressively discouraged. Furthermore, CAUTI does not always warrant antibiotic treatment because it is usually asymptomatic [most cases (90\%) of bacteriuria during catheterization are asymptomatic and usually resolves after removal of the catheter [35]. Patients catheterized for longer durations develop bacteriuria whether treated or not - the risk increasing by $5 \%$ per day [35]. Hence antibiotic prophylaxis just to prevent bacteriuria is not recommended unless the clinical situation demands it. "However, when an episode of CAUTI becomes symptomatic, the resulting sequelae can range from mild (fever, urethritis, and cystitis) to severe (acute pyelonephritis, renal scarring, calculus formation, and bacteremia). Left untreated, these infections can lead to urosepsis and death" $[36,37]$. "These complicated infections commonly recur and result in long-term morbidity due to the presence of encrustation and blockage of the catheter by crystalline biofilms that increase resistance to the host immune response and to antibiotics" [38].

Based on the findings of our study, we observed high rates of drug resistance in our setting indicating the urgent need for antibiotic stewardship. Another notable finding was the susceptibility of a high percentage of ESBL producing Escherichia coli to Nitrofurantoin, which is less often used though it is cheap and freely available in our setting.

\section{CONFLICT OF INTEREST}

The authors confirm that this article content has no conflict of interest.

\section{ACKNOWLEDGEMENTS}

We thank Dr. Venugopalan, Dean, Kannur Medical College, Anjarakandy, Dr. Sudarsana J., Professor and Head, Department of Microbiology and Dr. Anand Kumar, Medical Superintendent, KMC Hospitals for their support and encouragement.

\section{REFERENCES}

[1] Cox CE. Nosocomial urinary tract infections. Urology 1988; 32: 210-5.

[2] Tambyah PA, Maki DG. Catheter-associated urinary tract infection is rarely symptomatic: a prospective study of 1,497 catheterized patients. Arch Intern Med 2000; 160: 678-82.

[3] Hartstein AI, Garber SB, Ward TT, Jones SR, Morthland VH Nosocomial urinary tract infection: a prospective evaluation of 108 catheterized patients. Infect Control 1981; 2: 380-86.

[4] Centers for Disease Control and Prevention. Public health focus: surveillance, prevention, and control of nosocomial infections. Morb Mortal Wkly Rep 1992; 41: 783-7.

[5] Jarvis WR. Selected aspects of the socioeconomic impact of nosocomial infections: morbidity, mortality, cost, and prevention. Infect Control Hosp Epidemiol 1996; 17: 552-7.

[6] Chenoweth CE, Saint S. Infect Dis Clin N Am 2011; 25: 103-15. 
[7] Struelens MJ. The epidemiology of antimicrobial resistance in hospital acquired infection: problems and possible solutions. BMJ 1998; 317: 652-4

[8] Bhat GK, Ninan R, Mallya S. Floroquinolone resistant bacteria in nosocomial UTI. Trop Doctor 1998; 10: 250-1.

[9] Mohanty S, Kapil A, Das BK, Dhawan B. Antimicrobial resistance profile of nosocomial uropathogens in a tertiary care hospital. Ind $\mathrm{J}$ Med Sci 2003; 57: 148-54.

[10] Alhambra A, Cuadros JA, Cacho J, Gómez-Garcés JL, Alós JI. In vitro susceptibility of recent antibiotic-resistant urinary pathogens to ertapenem and 12 other antibiotics. J Antimicrob Chemother 2004; 53: 1090-4

[11] Livermore DM, Canton R, Gniadkowski M, et al. CTX-M: changing the face of ESBLs in Europe. J Antimicrob Chemother 2007; 59: 165-74.

[12] Hsueh PR, Hoban DJ, Carmeli Y, et al. Consensus review of the epidemiology and appropriate antimicrobial therapy of complicated urinary tract infections in Asia-Pacific region. J Infect 2011; 63: $114-23$.

[13] Mahesh E, Ramesh D, Indumathi VA, Punith K, Raj Kirthi, Anupama HA. Complicated urinary tract infection in a tertiary care center in South India. Al Ameen J Med Sci 2010; 2: 120e7.

[14] De Francesco MA, Ravizzola G, Peroni L, Negrini R, Manca N. Urinary tract infections in Brescia, Italy: etiology of uropathogens and antimicrobial resistance of common uropathogens. Med Sci Monit 2007; 13: 136-44.

[15] Kunin CM. Nosocomial urinary tract infections and the indwelling catheter. What is new and what is true? Chest 2001; 120: 10-2.

[16] Morrison AJ, Wenzen RP. Nosocomial urinary tract infections due to enterococcus. Ten years experience at a university hospital. Arch Intern Med 1986; 146: 1549-51.

[17] Garner JS, Jarvis WR, Emori TG, Horan TC, Hughes JM. CDC definitions for nosocomial infections. Am J Infect Control 1988; 16: $128-40$.

[18] Bryan CS, Reynolds KL. Hospital-acquired bacteremic urinary tract infection: epidemiology and outcome. J Urology 1984; 132: 494-98.

[19] Hashmi S, Kelly E, Rogers SO, Gates J. Urinary tract infection in surgical patients. Am J Surg 2003; 186: 53-6.

[20] Koneman EW, Allen SD, Janda WM, Schreckenberger PC, Winn WC Jr, Eds. Colour atlas and textbook of diagnostic microbiology. $5^{\text {th }}$ ed. Philadelphia: Lippincott 1997; pp. 139-40.

[21] Koneman EW, Allen SD, Janda WM, Schreckenberger PC, Winn Jr WC, Eds. Colour Atlas and Textbook of Diagnostic Microbiology. $5^{\text {th }}$ Ed. Philadelphia: Lippincott 1997; pp. 233.

[22] Clinical and Laboratory Standards Institute: M100-S20-U. Performance standards for antimicrobial susceptibility testing: $20^{\text {th }}$ informational supplement. Wayne, PA: CLSI 2010.
[23] Magiorakos AP, Srinivasan A, Carey RB, et al. Multidrugresistant, extensively drug-resistant and pandrug-resistant bacteria: an international expert proposal for interim standard definitions for acquired resistance. Clin Microbiol Infect 2012; 18(3): 268-81.

[24] Swenson JM, Hindler JA, Peterson LR. Special tests for detecting antibacterial resistance. In: Murray PR, Ed. Manual of clinical microbiology. $6^{\text {th }}$ ed. Washington DC: ASM Press 1995; pp. 135667

[25] Warren JW. Nosocomial urinary tract infections. In: Mandell GL, Bennett JE, Dolin R, Eds. Mandell, Douglas, and Bennett's Principles and practice of infectious diseases. $5^{\text {th }}$ ed. Philadelphia: Churchill Livingston 2000; pp. 3028-39.

[26] Maki DG, Tambyah PA. Engineering out of the risk of infection with urinary catheters. CDC: Emerg Infect Dis 2001; 7: 2 .

[27] Garibaldi PA, Burke JP, Dickman MC, et al. Factors predisposing to bacteriuria during indwelling urethral catheterization. N Eng J Med 1974; 291: 215

[28] Platt R, Polk BF, Murdock B, Rosner B. Risk factors for nosocomial urinary tract infection. Am J Epidemiol 1986; 124: 977-85.

[29] Shapiro M, Simchen E, Izreli S, et al. A multivariate analysis of risk factors for acquiring bacteriuria in patients with indwelling urinary catheters for longer than 24 hours. Infect Control 1984; 5: 525-32.

[30] Carson CC. Nosocomial urinary tract infections. Surg Clin N Am 1988; 68: 1147-55.

[31] Stamm WE. Nosocomial urinary tract infections. In: Bennett JV, Brachman PS, Sanford JP, Eds. Hospital Infections. $3^{\text {rd }}$ ed. Boston: Little Brown and Company 1992; pp. 597-610.

[32] Sussman M. Escherichia coli and human disease. In: Sussman M, Ed. Escherichia coli mechanism of virulence. UK: Cambridge University Press, 1997; p. 524.

[33] Ikaheimo R, Siitonem A, Karkkainess U, Makela H. Virulence characteristics of Escherichia coli in nosocomial urinary tract infection. Clin Infect Dis 1993; 16: 785-91.

[34] Tsuchimori N, Hayashi R, Shino A, Yamazaki J, Okonogi K. Enterococcus faecalis aggravates pyelonephritis caused by Pseudomonas aeruginosa in experimental ascending mixed urinary tract infection in mice. Infect immun 1994; 62: 4534-41.

[35] Saint S, Lipsky BA. Preventing catheter - related bacteriuria Should we? Can we? How? Arch Intern Med 1999; 159: 800-8

[36] Niel-Weise BS, van den Broek PJ. Urinary catheter policies for long-term bladder drainage. Cochrane Database Syst Rev 2005; CD004201.

[37] Warren JW. Catheter-associated urinary tract infections. Infect Dis Clin N Am 1997; 11: 609-22.

[38] Stickler DJ, Zimakoff J. Complications of urinary tract infections associated with devices used for long-term bladder management. J Hosp Infect 1994; 28: 177-94. 